\title{
Bottlenecks and barriers to effective coverage of early childhood health and development interventions in Guatemala: A scoping review
}

\author{
Kayla Marra ${ }^{1}$ and Isabel Espinosa ${ }^{2}$
}

Suggested citation Marra K, Espinosa I. Bottlenecks and barriers to effective coverage of early childhood health and development interventions in Guatemala: A scoping review. Rev Panam Salud Publica. 2020;44:e105. https://doi.org/10.26633/RPSP.2020.105

ABSTRACT Objectives. To identify bottlenecks and barriers to effective coverage by Early Childhood Health and Development (ECHD) interventions in Guatemala.

Methods. A scoping review of more than 100 peer-reviewed articles, grey literature, and other academic publications was conducted. Articles published from 2005-2019 were considered. Results were analyzed using the Tanahashi model of effective coverage that categorizes coverage by five domains: availability, accessibility, acceptability, contact, and effective coverage.

Results. A total of 103 articles were identified, addressing 337 bottlenecks and barriers to effective coverage by ECHD interventions in Guatemala. Most occurred along the acceptability dimension (35.9\%). The findings revealed four opportunity spaces: (i) strong political interest and commitment (opportunity for leadership); (ii) vibrant community health networks (opportunity for leverage); (iii) availability of promising evidence-based projects and interventions (opportunity for scale-up); and (iv) strong agency presence (opportunity for collaboration).

Conclusions. Most bottlenecks and barriers to ECHD interventions in Guatemala occur around acceptability, followed by accessibility and availability. There is considerable potential for national leadership, leverage, scale-up, and collaboration of ongoing efforts in the country. These results may be used to inform future research and policymaking. The Tanahashi approach is an effective lens of analysis that can be applied to other countries, geographic areas, and contexts in future studies.

Keywords Health equity; maternal health; child health; developing countries; Guatemala.

Over the last few decades, Guatemala has made significant gains in standards of living and measurements of health. Gross domestic product (GDP) per capita has grown from US\$ 826 in 1990 to US\$ 4471 in 2017, exceeding that of El Salvador, Honduras, and Nicaragua (1). However, the multidimensional nature of poverty is still significant when other factors, such as health, education, and housing are considered (2). From 1990 - 2017, life expectancy grew by 11 years and educational attainment doubled, contributing to a $36 \%$ increase on the
Human Development Index (3). Early Childhood Health and Development (ECHD) is a critical window that determines future chances and outlooks for the next generation (4). Ensuring a healthy start is, therefore, a global priority codified by the Sustainable Development Goals, as well as a national priority for Guatemala $(5,6)$. Regarding ECHD indicators, the country has realized important achievements. Since 1990, there have been significant decreases in neonatal, infant, and under-5 mortality rates-from $29 \%, 60 \%$, and $82 \%$ to $14 \%, 24 \%$, and $29 \%$ in

\footnotetext{
1 Paul H. Nitze School of Advanced International Studies, Johns Hopkins University, Washington, DC, United States of America. $\square$ Kayla Marra, kmarra3@jhu.edu
} \begin{tabular}{l}
\hline Pan American Health Organization/World Health Organization, Washington, \\
DC, United States of America.
\end{tabular} 
2016, respectively (7). Chronic malnutrition (stunting) among children under 5 years of age has decreased from $57.8 \%$ in 1987 to $46.5 \%$ in 2015 (8).

Despite this progress, gains have been inequitably distributed and specific groups-particularly those living in rural and indigenous communities-continue to experience significant ECHD inequities. For example, by department, the rate of under-5 stunting ranges from a low of $25.3 \%$ in Guatemala province to a high of $70 \%$ in Totonicapán province (8). By place of residence, this gap is $35 \%$ urban to $53 \%$ rural (9). By ethnicity, the rates are $34 \%$ for non-indigenous compared to $58 \%$ among indigenous (9). These patterns are replicated for under-5 and neonatal mortality rates. Maternal mortality estimates by sub-population are less readily available, but 2007 figures place the indigenous to non-indigenous ratio at 2.12, that is, 163 vs. 77 deaths per 100000 live births (10).

These persistent gaps are troubling. To reduce these inequities, it is necessary not only to identify who is being left behind, but why. This review seeks to fill this knowledge gap by systematically identifying bottlenecks and barriers to effective coverage of ECHD interventions in Guatemala. The aim is to present a broad and comprehensive survey of the current literature, applying the Tanahashi framework of effective coverage (defined in the Methods). By doing so, we hope to contribute to the growing body of global and regional work on health inequities, and provide evidence and recommendations that can be used to support decisionmakers, program managers, and stakeholders in better understanding and addressing the factors that influence coverage loss. By mapping this profile, we hope to provide a platform that can be used to craft highimpact, equity-based solutions going forward.

\section{MATERIALS AND METHODS}

A scoping review was conducted to identify articles on supply-side bottlenecks and demand-side barriers to effective coverage of ECHD interventions in Guatemala. A list of relevant critical/sensitive periods, indicators, and essential health interventions was generated in consultation with Regionaland national-level Pan American Health Organization/World Health Organization (PAHO/WHO) staff to ensure that this review would capture the full continuum of care-from preconception through the early formative years. To externally validate the methodology, the research team traveled to Guatemala City to consult with key stakeholders across diverse sectors, including representatives from the Ministries of Health; Education; Social Development; Agriculture, Livestock, and Food; Food Security and Nutrition; Care for Persons with Disabilities; and the Presidential Secretariat for Women. After presenting preliminary results, the methodology was confirmed as appropriate for the Guatemalan context and feedback was incorporated to refine the search terms.

The search terms were derived from combinations of the following phrase, "bottlenecks OR barriers AND Guatemala AND..." each of the key words appearing in Table 1 (11). Searches were conducted in English using the following databases: Cochrane Central Register of Controlled Trials (CENTRAL; The Cochrane Collaboration, London, United Kingdom), EMBASE (Excerpta Medica Database, Elsevier, Amsterdam, the Netherlands), CINAHL (Cumulative Index to Nursing and Allied Health Literature, EBSCO Information Services, Ipswich, MA, United States), PsycInfo ${ }^{\circledR}$ (American Psychological Association, Washington, DC, United States), BIOSIS Previews ${ }^{\circledR}$ (EBSCO Information Services, Ipswich, MA, United States), PubMed Central (U.S. National Library of Medicine, Bethesda, MD, United States), Web of Science ${ }^{\mathrm{TM}}$ (Clarivate Analytics, Philadelphia, PA, United States), Google Scholar (Google Inc., Mountain View, CA, United States), SciELO (Latin American and Caribbean Center on Health Sciences Information, São Paulo, Brazil), and LILACS (Latin American and Caribbean Center on Health Sciences Information, PAHO/WHO, São Paulo, Brazil).

Articles that met the following criteria were included: (i) published in 2005 - 2019; (ii) abstract containing information relevant to bottlenecks and barriers to effective coverage of ECHD interventions; and (iii) results specific to Guatemala. A preliminary search (updated 16 April 2020) yielded 1009 results that were narrowed down to 103. The most common reason for excluding an article was that the results were not specific to Guatemala. To ensure that the review captured the maximum quantity of relevant findings, grey literature was allowed where appropriate. Further, articles were not excluded for methodology nor rigor. Rather, articles were filtered by the

TABLE 1. List of critical/sensitive periods, indicators, and health interventions that were used in a search for a scoping review of bottlenecks and barriers to effective coverage of early childhood health and development interventions in Guatemala, 2005-2019

\begin{tabular}{|c|c|c|}
\hline 6 Critical/ Sensitive Periods & 11 Relevant Health Indicators & $\begin{array}{l}15 \text { Health and Development Interventions for Comprehensive } \\
\text { Early Childhood Care }\end{array}$ \\
\hline $\begin{array}{l}\text { - Adolescence } \\
\text { - Preconception } \\
\text { - Maternity } \\
\text { - Birth } \\
\text { - Neonatal } \\
\text { - } 0-5 \text { years }\end{array}$ & $\begin{array}{l}\text { - Adolescent birth rate (10-14 and 15-19 years) } \\
\text { - Demand for family planning with modern methods satisfied (15-19 } \\
\text { - } \text { years) } \\
\text { - } \text { years) } \\
\text { - Pregnant women with anemia (15-19 and } 15-49 \text { years) } \\
\text { - Antenatal care-4 or more visits (15-19 and 15-49 years) } \\
\text { - Births attended by skilled health personnel (15-19 and 15-49 years) } \\
\text { - Neonatal mortality } \\
\text { - Prevalence of low birth weight } \\
\text { - Under } 5 \text { mortality rate } \\
\text { - Children under } 5 \text { with chronic malnutrition (stunting) } \\
\text { - Exclusive breastfeeding for infants under } 6 \text { months }\end{array}$ & $\begin{array}{l}\text { - } \text { Comprehensive sexuality education } \\
\text { - } \text { Antenily planning services } \\
\text { - Detection and treatment of syphilis } \\
\text { - Detection and treatment of asymptomatic bacteriuria } \\
\text { - Antibiotics for preterm premature rupture of membranes } \\
\text { - Resuscitation of newborn } \\
\text { - Kangaroo mother care } \\
\text { - Early initiation of breastfeeding } \\
\text { - Hemophilus influenzae B and pneumococcal immunization } \\
\text { - Deworming during and after diarrhea } \\
\text { - Zinc supplementation for treatment of acute diarrhea } \\
\text { - Exclusive breastfeeding for the first } 6 \text { months of life } \\
\text { - Supplementation and fortification of staple foods }\end{array}$ \\
\hline
\end{tabular}

Source: Prepared by the authors in consultation with PAHO/WHO staff, and adapted from Reference 11. 


\section{BOX 1. Definitions and examples of the five domains that are required to achieve effective coverage}

Availability: A sufficient quantity of basic public health inputs.

Accessibility: Care must be accessible physically, financially, informationally/organizationally, and without discrimination.

Acceptability: Refers to perceptions of cultural compatability. Contact: Actual contact between the service provider and the user. Effective Coverage: Care is utilized sufficiently such that treatment aim is met.

Source: Prepared by the authors, adapted from References $12-14$
Examples: Potable water, adequate sanitation, hospitals, clinics, trained medical personnel, essential medicines.

Examples: Travel time, costs at the point of service, operating hours, wait times, language accessibility.

Examples: Care is sensitive to gender, life stage, and ethnicity.

Examples: User awareness and perceptions of health needs.

Examples: Diagnostic accuracy, provider compliance, treatment adherence, effective referral systems. authors (KM, IE) according to pertinent information found in the abstracts. A complete list of the reviewed articles may be found in the Supplementary material.

After selecting and reviewing the relevant articles, the bottlenecks and barriers described were categorized according to the five stages of effective coverage, adapted from the Tanahashi model (12). The model outlines the five stages that are sequentially required to achieve effective coverage of a desired intervention: availability, accessibility, acceptability, contact, and effective coverage (Box 1 ). Worth noting is that these dimensions overlap, and mediating factors, such as discrimination or quality, may be cross-cutting $(13,14)$. By delineating the components of effective coverage, the model allows the analyst to more precisely identify where the greatest coverage loss occurs and recommend appropriate solutions. Furthermore, Tanahashi points out that expansion of coverage along one dimension may not necessarily improve effective coverage overall, particularly if bottlenecks and barriers occur upstream.

\section{RESULTS}

A total of 103 articles were identified, which together addressed 337 bottlenecks and barriers to effective coverage of ECHD interventions in Guatemala (Table 2; for a complete list of material reviewed, see Supplementary material). Of these, 35 studies $(34.0 \%)$ employed qualitative methods, 31 studies $(30.1 \%)$ used quantitative methods, 21 studies $(20.4 \%)$ used mixed methods, and 4 were literature reviews (3.9\%). The remaining 12 publications labeled "other/not specified" were mainly grey literature, including agency reports, technical briefs, fact sheets, and working papers, whose methods were not always explicitly stated. The geographic area of interest was identified in $70 \%$ of the studies (Table 3). The studies were primarily focused on Guatemala's Western Highland areas of Huehuetenango, Quetzaltenango, Quiché, San Marcos, Sololá, or Totonicapán (38 studies, 36.9\%). Thirteen studies were conducted on a national level $(12.6 \%)$. Additionally, data were collected on the ethnic population or residential area of interest, when specified. Most studies (50.5\%) focused on indigenous (primarily Mayan) groups, while only 2 were specific to ladinos. Similarly, more than one-half were concerned with rural areas, while only 1 specified an urban focus.

\section{Tanahashi model findings}

Figure 1 summarizes the study findings according to Tanahashi dimension. The majority of bottlenecks and barriers
TABLE 2. Selected articles, by publication type and methodology in a scoping review of bottlenecks and barriers to effective coverage of early childhood health and development interventions in Guatemala, 2005-2019

\begin{tabular}{|c|c|c|c|c|}
\hline $\begin{array}{l}\text { Unique articles } \\
\text { identified }\end{array}$ & \multicolumn{2}{|c|}{ Publication type } & \multicolumn{2}{|c|}{ Methodology } \\
\hline 103 & $\begin{array}{l}\text { Peer-reviewed } \\
\text { Grey literature } \\
\text { Other academic } \\
\text { Website/blog } \\
\text { Book chapter }\end{array}$ & $\begin{array}{r}66 \\
23 \\
7 \\
5 \\
2 \\
\end{array}$ & $\begin{array}{l}\text { Qualitative } \\
\text { Quantitative } \\
\text { Mixed methods } \\
\text { Other/ not specified } \\
\text { Literature reviews }\end{array}$ & $\begin{array}{r}35 \\
31 \\
21 \\
12 \\
4 \\
\end{array}$ \\
\hline Total & & 103 & & 103 \\
\hline
\end{tabular}

Source: Prepared by the authors from the study results.

identified were concentrated around acceptability $(121 ; 35.9 \%)$, followed by accessibility (90; 26.7\%), and availability (72; $21.4 \%$ ). Conversely, bottlenecks and barriers to contact and effective coverage accounted for only $9.2 \%$ and $6.8 \%$ of the results, respectively. The following sections provide a more detailed analysis and brief discussion for each dimension.

Availability. Of the 103 studies, 46 (44.7\%) identified 72 availability-related bottlenecks and barriers (21.4\%). The most frequent were a shortage of resources or infrastructure, followed by a shortage of appropriately-trained health personnel. For example, the United Nations Children's Fund (UNICEF) 2017 annual report revealed that chronic vaccine shortages kept coverage levels low: $61 \%$ for diphtheria-pertussistetanus (DPT) and 64\% for measles vaccines, well below the recommended minimum of $80 \%$ (15).

Accessibility. Along this dimension, the review identified a total of 42 studies (40.8\%) mentioning 90 bottlenecks and barriers $(26.7 \%)$. Those most cited were direct or indirect financial costs (e.g., out-of-pocket payments and the opportunity-cost of missed work, respectively), followed by geographic barriers, language barriers, and excessive wait times. Also included in this category were instances of provider discrimination, when the provider clearly failed to deliver a service; for example, a study which found that $13 \%$ of providers would not supply contraception to women without their husband's consent (16). Another study reported that condoms were often not sold to Mayan adolescent girls due to their age, gender, and ethnicity (17). In these ways, discrimination acts as a supply-side bottleneck, but discrimination can also serve as a barrier to demand, which falls under the next dimension (acceptability). Language 
TABLE 3. Distribution of studies by geography, ethnicity, and residence, in a scoping review of bottlenecks and barriers to effective coverage of early childhood health and development interventions in Guatemala, 2005-2019, with inset showing geographic distribution by department

\begin{tabular}{|c|c|c|c|c|c|}
\hline \multicolumn{2}{|l|}{ Department or region } & \multicolumn{2}{|l|}{ Ethnicity } & \multicolumn{2}{|l|}{ Residence } \\
\hline National & 13 & Indigenous & 52 & Rural & 52 \\
\hline Western Highlands (not specified) & 4 & Indigenous and non-indigenous & 22 & Rural and Urban & 19 \\
\hline Not specified & 30 & Ladino & 2 & Urban & 1 \\
\hline & & Not specified & 27 & Not specified & 31 \\
\hline Department & & & & & \\
\hline Guatemala (GU) & 12 & Total & 103 & Total & 103 \\
\hline Huehuetenango (HU) & 12 & & & & \\
\hline Chimaltenango (CM) & 11 & & & & \\
\hline Sololá (SO) & 11 & & & & \\
\hline San Marcos (SM) & 9 & & & & \\
\hline Totonicapán (T0) & 8 & & & & \\
\hline Quetzaltenango (QZ) & 8 & & & & \\
\hline Quiché (QC) & 8 & & & & \\
\hline Alta Verapaz (AV) & 7 & & & & \\
\hline Chiquimula (CQ) & 6 & & & & \\
\hline Sacatepéquez (SA) & 4 & & & & \\
\hline Suchitepéquez & 4 & & & & \\
\hline Retalhuleu (RE) & 2 & & & & \\
\hline Baja Verapaz (BV) & 2 & & & & \\
\hline Izabal (IZ) & 2 & & & & \\
\hline El Progreso (PR) & 1 & & & & \\
\hline Santa Rosa (SR) & 1 & QZ - & & Frequency & \\
\hline Petén (PE) & 1 & ES & & & \\
\hline Zacapa (ZA) & 1 & su & & $i$ & $\begin{array}{c}12 \\
12\end{array}$ \\
\hline Jalapa (JA) & 1 & SA & & & \\
\hline Jutiapa (JU) & 1 & & & & \\
\hline Escuintla (ES) & - & & & & \\
\hline
\end{tabular}

Source: Prepared by the authors from the study results.

barriers were mentioned at least 16 times, representing nearly one-fifth of all accessibility bottlenecks and barriers. Among the Mayan population, an estimated 39\% of the national population, there are 21 unique languages spoken (18). At health facilities, it can be difficult to find bilingual staff or interpreters (19). Not only do language barriers cause feelings of alienation and negatively affect patient-provider relations, but serious miscommunications can occur that directly affect treatment adherence, informed consent, and diagnostic accuracy $(13,14)$.

Acceptability. A total of 58 studies (56.3\%) identified 121 bottlenecks and barriers (35.9\%) related to acceptability. Among these, the most common were cultural beliefs and myths, a lack of empowerment among women and girls to make decisions, rigid gender norms or machista culture, broader societal norms, distrust of government-provided services, perception of discrimination by providers, fear or embarrassment concerning treatment, social stigma, religious influences, and other cultural incompatibilities.

It was clear in this review that many of the bottlenecks and barriers surrounding gender, sex, and reproduction created a synergistic climate of stigmatization and taboo. In a society where women are not generally empowered, making deeply personal decisions regarding one's health are more complicated (20).
Together, these bottlenecks and barriers comprise two-fifths of the acceptability dimension and $15 \%$ of all bottlenecks and barriers identified in this review. Secondly, the country has prolific difficulties with providing culturally appropriate care to indigenous Mayans. The relevant bottlenecks and barriers here, in addition to language, are beliefs and myths, distrust, discriminatory attitudes by providers, and cultural incompatibilities. Together, these bottlenecks and barriers account for $38.8 \%$ of the acceptability dimension and $13.4 \%$ of the total.

Contact. Regarding this dimension, 27 studies (26.2\%) identified 31 bottlenecks and barriers $(9.2 \%)$. The most frequently cited was the user's lack of awareness of disease-related issues or the availability of interventions. Following this were instances of negative experiences occurring at the point of contact, preventing the continuation, recommendation, or future use of care. One such example described the lack of privacy and discretion adolescents received when visiting providers (21).

Effective Coverage. Along this final domain, 19 articles (18.4\%) identified 23 bottlenecks and barriers (6.8\%). Most related to issues with provider compliance, while a handful identified barriers to treatment adherence and problems with the referral 
FIGURE 1. Frequency of bottlenecks and barriers to effective coverage of early childhood health and development interventions identified by the Tanahashi model, by common themes, Guatemala, 2005-2019

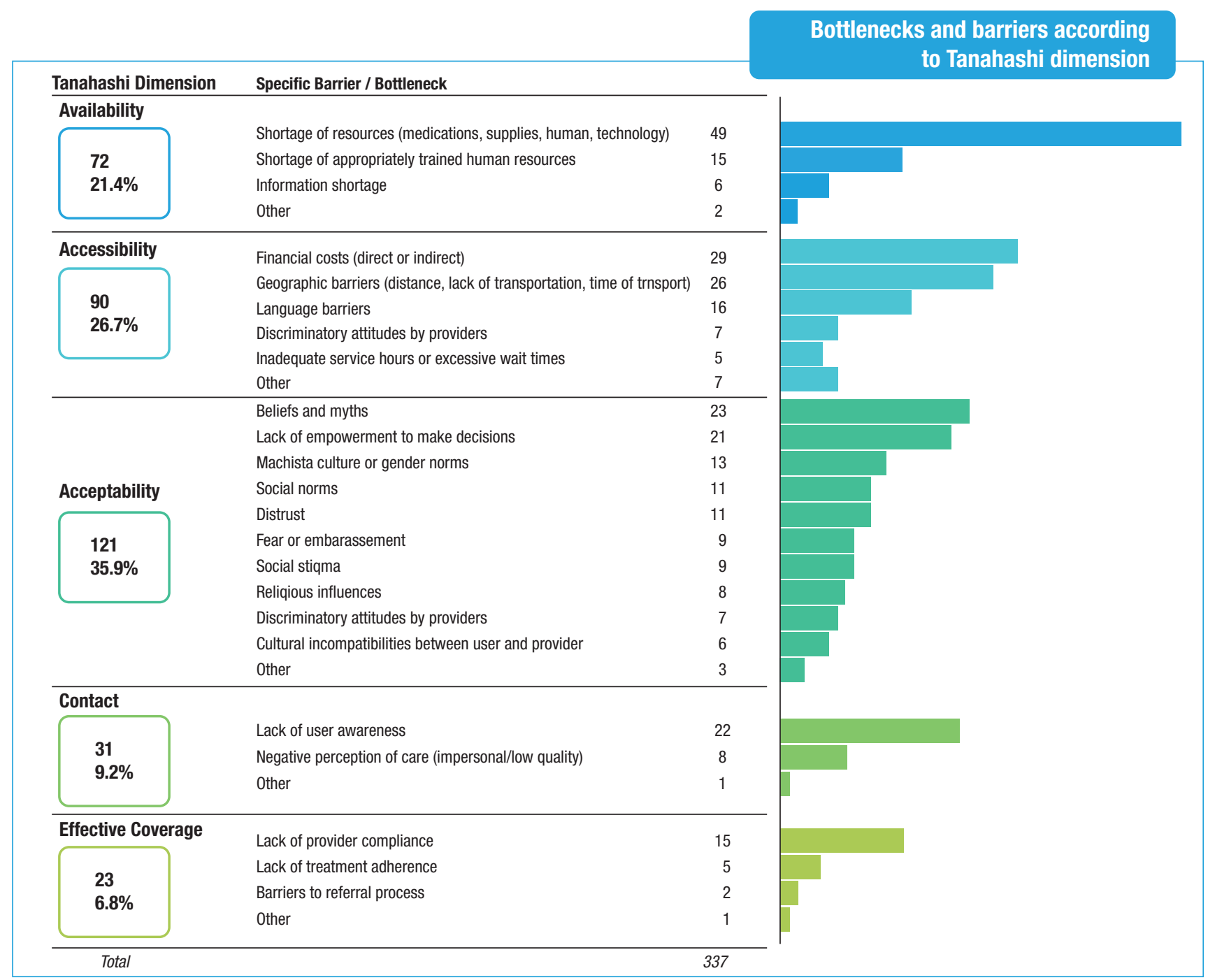

Source: Prepared by the authors from the study results.

process. One example of provider non-compliance was cited in an investigation of Klebsiella pneumoniae outbreaks within a neonatal intensive care unit, where it was revealed that staff improperly re-used single-use intravenous solutions (22).

\section{DISCUSSION}

Of more than 100 articles surveyed in this review, bottlenecks and barriers were found to occur along each dimension of the Tanahashi model. Nearly one-half of coverage loss was recorded in the first two dimensions, availability and accessibility. Indeed, the single most cited bottleneck or barrier that was identified overall was a shortage of resources/infrastructure. Based on available public sector data for Guatemala, in 2017 the country's physician density was just 2.8 per 10000 inhabitants, lower than any other Central American country (12.5 physicians) and much lower than the average (21.4 physicians) for Latin America and the Caribbean (23). Similarly, public health expenditure as a percentage of GDP was 2.2, compared to 3.8 for Central America and 3.7 for Latin America and the
Caribbean (23), and out-of-pocket expenditure as a percentage of total health expenditure was significantly greater at 53.3 versus 39.9 and 31.1, respectively (23). If budgetary and resource issues are not addressed in a meaningful and sustainable manner with appropriate leadership, oversight, and accountability, it is clear that coverage loss will continue to occur along these two primary stages.

Another interesting finding from our review was that over one-third of the identified bottlenecks and barriers occurred around the acceptability dimension. This may be driven by the fact that more than one-half of the studies identified were primarily concerned with indigenous communities, for whom culture is an essential part of daily life and decisionmaking. To adequately address the types of bottlenecks and barriers identified under this dimension, including discrimination, fear, and distrust, a continued and serious commitment at all levels will be required.

Although many of the bottlenecks and barriers identified are rooted in deep, historical and structural drivers-suggesting that any meaningful solutions will require a long-term 
horizon-there are plenty of opportunities for progress in the short-term. In particular, we observed the following opportunity spaces. First, as evidenced by the existing national multisectoral working group on ECHD, as well as the available ECHD public policy, we noted a strong political interest and commitment by the Government of Guatemala, presenting the opportunity for continued leadership, not only with regard to ECHD, but also to measuring and addressing health inequities using a life course approach (6). Second, we noted the strong presence of community health networks composed of local volunteers, facilitators, and practitioners who are readily accepted by the community, fluent in the native language(s), and geographically proximal, e.g., the comadronas (24, 25). These networks should be empowered and treated as partners to leverage their ties to hard-to-reach communities. Third, we identified several examples of ongoing, evidence-based projects and interventions that show potential for scale-up. For example, several studies found positive results implementing mobile health (m-health) interventions to reach populations that live in rural or remote locations $(26-28)$. Finally, our review frequently encountered a strong presence and commitment from other international actors, indicating the opportunity for continued collaboration and coordination of limited resources.

Limitations. By design, these results are highly specific to the Guatemalan context and may not be applicable to other low- and middle-income countries. However, the model of analysis proved useful and can be replicated in other areas. Additionally, in an effort to depict a comprehensive landscape of bottlenecks and barriers to ECHD interventions, the results are rather broad. There is a tradeoff between breadth and depth, and further insights may be gained by examining a specific intervention. Also, the results are largely descriptive. Although the search was conducted systematically, the findings must be viewed through the lens of studies that could be identified. There are likely more studies, and therefore we cannot make statistical inferences regarding bottlenecks and barriers at this time. Finally, most studies identified were concerned with rural and indigenous groups. Bottlenecks and barriers are likely different for urban or peri-urban dwellers, afro-descendants, migrants, disabled persons, and other vulnerable groups, requiring further investigation.

\section{CONCLUSIONS}

Using the Tanahashi framework for effective coverage, this review determined that most bottlenecks and barriers to ECHD interventions in Guatemala occur around acceptability, followed by accessibility and availability. There appeared to be broad consensus among the literature regarding where bottlenecks and barriers exist, and how they are linked. Additionally, this review revealed a considerable potential for national leadership, leverage, scale-up, and collaboration of ongoing efforts in the country. Addressing persistent coverage loss is a significant and ongoing challenge to the public health system and its partners in Guatemala; however, employing a domain analysis and equity approach can help prioritize their efforts.

Author contributions. IE conceived the original idea and planned the experiments. Both authors collected the data and KM provided data analysis and interpretation. KM wrote the paper, which was reviewed by IE. Both authors reviewed and approved the final version.

Acknowledgements. We would like to thank the following persons at $\mathrm{PAHO} / \mathrm{WHO}$ for their support in the implementation of this work and in the development of this document: Amalia Ayala, Coordinator Family, Health Promotion and Life Course in Guatemala; Cecilia Escobar, National Consultant in Guatemala; Enrique Vega, Regional Unit Chief, Healthy Life Course; Carolina Hommes, Regional Technical Officer, Healthy Life Course; Antonio Sanhueza, Regional Advisor, Health Analysis; Pablo Duran, Regional Neonatal Health Advisor; Bremen de Mucio, Regional Maternal Health Advisor; Betzabe Butron, Regional Child Health Advisor; and Sonja Caffe, Regional Adolescent Health Advisor.

\section{Conflicts of interest. None declared.}

Disclaimer. Authors hold sole responsibility for the views expressed in the manuscript, which may not necessarily reflect the opinion or policy of the RPSP/PAJPH and/or PAHO.

\section{REFERENCES}

1. World Bank Group. World Bank Open Data. Available from: https:/ / data.worldbank.org/ Accessed 12 August 2019.

2. Multidimensional Poverty Peer Network. Available from: https:// mppn.org/paises_participantes/guatemala/ Accessed 21 May 2020.

3. United Nations Development Program. Human Development Indices and Indicators: 2018 Statistical Update. New York: UNDP; 2018. Available from: http://hdr.undp.org/en/data Accessed 20 August 2019.

4. Commission on Social Determinants of Health. Closing the gap in a generation: health equity through action on the social determinants of health. Final Report of the Commission on Social Determinants of Health. Geneva: World Health Organization; 2008.

5. United Nations Children's Fund. The 2030 Agenda for Sustainable Development. New York: UN. Available at: https://www.unicef. org/agenda2030/69525.html Accessed on 20 August 2019.
6. Instituto Interamericano del Niño la Niña y Adolescentes. Guatemala invierte en desarrollo integral de la primera infancia 2010-2020. Available from: https://www.siteal.iiep.unesco.org/ sites/default/files/sit_accion_files/siteal_guatemala_0754.pdf Accessed 4 June 2020

7. United Nations Inter-agency Group for Child Mortality Estimation. Levels and Trends in Child Mortality: Report 2017. Estimates Developed by the UN Inter-agency Group for Child Mortality Estimation. New York: UN; 2017.

8. Ministerio de Salud Pública y Asistencia Social, Instituto Nacional de Estadística, Secretaría de Planificación y Programación de la Presidencia. Encuesta Nacional de Salud Materno Infantil 2014-2015. Available from: https:/ /www.ine.gob.gt/images/2017/ encuestas/ensmi2014_2015.pdf Accessed 12 August 2019.

9. United Nations Children's Fund. EQUIST. Available from: https:// www.equist.info/en/pages/home Accessed 20 August 2019. 
10. Ministerio de Salud Pública y Asistencia Social, Secretaría General de Planificación de la Presidencia de la República. Estudio Nacional de Mortalidad Materna en Guatemala: ENMM 20072011. Available from: https://www.paho.org/gut/index.php? option=com_docman\&view $=$ download $\&$ alias $=566-2011$-estudiomortalidad-materna-2007-segeplan-ops\&category_slug=sfc-saludreproductiva-materna-y-neonatal-nacional\&Itemid $=518$ Accessed 12 August 2019.

11. Pan American Health Organization, Texas Children's Hospital. Evidence-based Interventions in the context of the care continuum for mothers, newborns, and infants. Neonatal IMCI. 2011. Available from: https://www.paho.org/hq/dmdocuments/2012/NeonatalIMCI-evidence-based-interventions-INBE-eng-2012.pdf Accessed 9 August 2019.

12. Tanahashi T. Health service coverage and its evaluation. Bull World Health Organ. 1978;56:295-303.

13. World Health Organization. The Innov8 approach for reviewing national health programmes to leave no one behind?: technical handbook. Geneva: WHO; 2016.

14. World Health Organization. Handbook for conducting an adolescent health services barriers assessment (AHSBA) with a focus on disadvantaged adolescents. Geneva: WHO; 2019. Available from: https://www.who.int/gender-equity-rights/knowledge/ adolescent-health-services-barriers-assessment/en/ Accessed 18 May 2020.

15. United Nations Children's Fund. UNICEF Annual Report 2017 for Guatemala. New York:UN; 2017.

16. United States Agency for International Development. Deliver Project. Using Geographic Information System tools to address disparities in access to family planning services and commodities in Latin America and the Caribbean. 2008. Available from: https:/ / pdfs.semanticscholar.org/7762/3b1595b29b1e600c5084b 7d0c05e676faf46.pdf Acessed 9 August 2019.

17. Wehr H, Tum SE. When a girl's decision involves the community: The realities of adolescent Maya girls' lives in rural indigenous Guatemala. Reprod Health Matters. 2013;21:136-42.

18. World Population Review. Guatemala Population 2019. Available from: http://worldpopulationreview.com/countries/guatemalapopulation/ Accessed 14 August 2019.

19. Juarez M, Austad K, Rohloff P. Lay midwives: on the front lines of the fight against maternal mortality in rural Guatemala. Am J Trop Med Hyg. 2019;100:237-8.

20. Becker S, Fonseca-Becker F, Schenck-Yglesias C. Husbands' and wives' reports of women's decision-making power in Western
Guatemala and their effects on preventive health behaviors. Soc Sci Med. 2006;62:2313-26.

21. Guttmacher Institute. Sexual and Reproductive Health Of Young Women in Guatemala: Demystifying Data. Available from: https:// www.guttmacher.org/fact-sheet/sexual-and-reproductive-health-yo ung-women-guatemala Accessed 9 August 2019.

22. Gray J, Arvelo W, McCracken J, Lopez B, Lessa FC, Kitchel B et al. An outbreak of Klebsiella pneumoniae late-onset sepsis in a neonatal intensive care unit in Guatemala. Am J Infect Control. 2012;40:516-20.

23. Pan American Health Organization. Core Indicators 2019: Health Trends in the Americas. 2019. Available from: https://iris.paho org/bitstream/handle/10665.2/51542/9789275121290_eng.pdf? sequence $=6 \&$ is Allowed $=y$ Accessed 21 May 2020.

24. Hernandez S, Oliveira JB, Shirazian T. How a training program is transforming the role of traditional birth attendants from cultural practitioners to unique health-care providers: A community case study in rural Guatemala. Front Public Heal. 2017;5:111.

25. Chaudhry S, Oliveira J, Shirazian T. The emerging role of the comadrona as a broker between ancient cultural beliefs and modern biomedicalization to improve maternal health care in Guatemala In: Schwartz D, eds. Maternal Death and Pregnancy-Related Morbidity Among Indigenous Women of Mexico and Central America. doi: 10.1007/978-3-319-71538-4_31

26. Martínez-Fernández A, Lobos-Medina I, Díaz-Molina CA, ChenCruz MF, Prieto-Egido I. TulaSalud: An m-health system for maternal and infant mortality reduction in Guatemala. J Telemed Telecare. 2015;21:283-91.

27. Prieto JT, Zuleta C, Rodríguez JT. Modeling and testing maternal and newborn care mHealth interventions: a pilot impact evaluation and follow-up qualitative study in Guatemala. J Am Med Informatics Assoc. 2016;24:102.

28. Domek GJ, Contreras-Roldan IL, O'Leary ST, Bull S, Furniss A, Kempe A et al. SMS text message reminders to improve infant vaccination coverage in Guatemala: A pilot randomized controlled trial. Vaccine. 2016;34:2437-43.

Manuscript received on 16 April 2020. Revised version accepted for publication on 11 June 2020 


\section{Obstáculos y barreras a una cobertura efectiva de intervenciones de salud y desarrollo en la primera infancia en Guatemala: revisión sistemática exploratoria}

RESUMEN Objetivos. Identificar los obstáculos y las barreras que impiden una cobertura efectiva de las intervenciones de salud y desarrollo en la primera infancia en Guatemala.

Métodos. Se llevó a cabo una revisión sistemática exploratoria de más de 100 artículos revisados por pares, literatura gris y otras publicaciones académicas. Se consideraron artículos publicados entre 2005 y 2019 . Los resultados se analizaron utilizando el modelo de Tanahashi de cobertura efectiva que clasifica la cobertura en cinco dominios: disponibilidad, accesibilidad, aceptabilidad, contacto y cobertura efectiva.

Resultados. Se identificaron 103 artículos que abordan 337 obstáculos y barreras a la cobertura efectiva de las intervenciones de salud y desarrollo en la primera infancia en Guatemala. La mayoría de ellos se produjeron en la dimensión de la aceptabilidad (35,9\%). Los resultados revelaron cuatro espacios de oportunidad para la acción: i) un fuerte interés y compromiso políticos (oportunidad de liderazgo); ii) redes de salud comunitarias dinámicas (oportunidad de apalancamiento); iii) disponibilidad de proyectos e intervenciones prometedores basados en la evidencia (oportunidad de ampliación); y iv) marcada presencia de instituciones (oportunidad de colaboración).

Conclusiones. La mayoría de los obstáculos y las barreras a las intervenciones de salud y desarrollo en la primera infancia en Guatemala se dan en torno a la aceptabilidad, seguida de la accesibilidad y la disponibilidad. Existe un considerable potencial para el liderazgo nacional, el apalancamiento, la ampliación y la colaboración entre los emprendimientos en curso en el país. Estos resultados pueden utilizarse para fundamentar futuras investigaciones y la formulación de políticas. El enfoque de Tanahashi es una herramienta de análisis eficaz que puede aplicarse a otros países, zonas geográficas y contextos en estudios futuros.

Palabras clave Equidad en salud; salud materna; salud del niño; países en desarrollo; Guatemala. 